\title{
A partial backlogging inventory model for deteriorating items with time-varying demand and holding cost: An interval number approach
}

\author{
Debashis Dutta $^{1, *}$ and Pavan Kumar ${ }^{2}$ \\ ${ }^{1}$ Department of Mathematics, National Institute of Technology \\ PIN 506004, Warangal, India \\ E-mail: 〈\{dduttamath, pavankmaths\}@gmail.com〉
}

\begin{abstract}
This paper proposes a differential equation inventory model that incorporates partial backlogging and deterioration. Holding cost and demand rate are time dependent. Shortages are allowed and assumed to be partially backlogged. Two versions are presented, the first one with deterministic values of the parameters and the second one taking into the account the interval uncertainty of the parameters. In the crisp case, Taylor's series expansion is used, and graphically shown that the cost function is convex. While, in the case of intervals, the interval arithmetic is used and then the problem is transformed into a multi-objective non-linear optimization problem and an interval objective function. To solve this problem, the weighted-sum method is used. The proposed procedure is validated with the help of a numerical example. Sensitivity analysis on various parameters has also been carried out.
\end{abstract}

Key words: inventory model, interval-valued number, weighted-sum method.

Received: September 13, 2014; accepted: May 18, 2015; available online: October 31, 2015

DOI: $10.17535 /$ crorr.2015.0025

\section{Introduction}

In inventory control problems, we normally deal with real numbers, which are assumed to have a fixed value. However, the real life inventory problems cannot be properly formulated in this way due to uncertainty. For example, inventory holding cost may vary in rainy seasons during the summer or winter seasons. The ordering cost, dependent on transportation facilities, may also vary from season to season. Changes in the prices of fuels, postal and telephone charges may also set the ordering cost as a variable. The unit purchase cost is highly dependent on the costs of raw materials and labor, and may fluctuate with time.

Moreover, the customer's demand also differs during various seasons. In literature surveyed, some authors considered that interval numbers deal with

${ }^{*}$ Corresponding author. 
these types of uncertainties. An interval number is an extension of the concept of a real number and also a subset of a real line [16]. Moreover, the the $\alpha$-cut of a fuzzy number is an interval number [26]. The nearest-interval approximation of a fuzzy number is proposed in [9]. Some algebraic properties and a distance measure for interval-valued fuzzy numbers are described in [10]. A (T, si)-policy inventory model for deteriorating items with time proportional demand is proposed in [6]. [11] introduces the interval objective function in multi-objective programming problems. A heuristic for replenishment of deteriorating items with a linear trend in time-dependent demand is proposed in [5].

Backlogging occurs due to shortages. Sometimes, researchers assumed partial backlogging while others considered full backlogging. In reality, if all customers are prepared to wait until the arrival of the next order, then it is called completely backlogged else, all the customers leave the system. However, in certain situations, some customers will be able to wait for the next order in order to satisfy their demands during the stock out period, while others do not wish to or cannot wait, hence they meet their demands from other sources (the partial backlogging case). The length of waiting time for replenishment is the main factor for determining backlogging and it has been found the longer the waiting time, the lower the backlogging rate. Customers who experience stockout may not purchase the goods again from the respective suppliers, and they may turn to another store to purchase the goods. Consequently, a larger proportion of sales is lost, leading to a smaller profit. As a result, taking into account the partial backlogging factor is necessary. This can also be fuzzy in nature [21].

The inventory models with shortages under a partial backlogging condition is proposed in $[1,2]$. An EOQ model for deteriorating items with time varying demand and partial backlogging is discussed in [4]. [24] developed a fuzzy inventory model with backorder for fuzzy total demand based on interval-valued fuzzy set. [23] presented an inventory model for deteriorating items with exponential declining demand and partial backlogging. The rate of deterioration is assumed constant and the backlogging rate is inversely proportional to the waiting time for the next replenishment.

Two inventory models are usually used in [7,8]: one for determining optimal selling price and lot size with a varying rate of deterioration and exponential partial backlogging, and other for joint pricing and ordering of a deteriorating inventory with partial backlogging. A study of the comparison between two pricing and lot-sizing models with partial backlogging and deteriorated items is presented in [22]. A model for fuzzy programming based on interval-valued fuzzy numbers and ranking is developed in [18].

The time varying holding cost and deteriorating items with price dependent demand is discussed in [17]. Differential equations for inventory models with ramp-type demand rate, partial backlogging and the Weibull deterioration rate are given in [19]. An inventory model for waiting time partial backlogging and 
deteriorating items is developed in [20]. [15] develops a deteriorating inventory model for time dependent demand and holding cost with partial backlogging. [3] proposes a purchasing inventory model with interval numbers.

In inventory problems, there are generally multiple objectives. [25] discusses the weighted-sum method to solve multi-objective problems. [14] proposes a production inventory model with shortages and interval value numbers, and finally a minimized the total inventory cost using the global criteria method. To minimize the interval cost function, the multi-objective optimization problem is normally formulated as the minimization of the center and right limit of the interval cost function $[12,13]$.

This paper proposes an inventory model. Some assumptions are considered in Section 2.2. The objective is to determine the optimum value of total average cost and optimum value of inventory-exhausting time. In case of interval uncertainty, we introduce the intervals to deduce the expression for average total cost. We formulated the multi-objective optimization problem as the minimization of left and right limit of the interval-valued cost function. Accordingly, the weighted-sum method is used to obtain a Pareto optimal solution [Sections 3, 4 \& 5]. An example is illustrated in Section 6 using sensitivity analysis. Finally, a concluding remark is made in Section 7.

\section{Notations and assumptions}

The proposed model is developed under the following notations and assumptions:

\subsection{Notations}

\begin{tabular}{|c|c|c|c|}
\hline$T$ & Cycle time (decision variable) & $t_{1}$ & $\begin{array}{c}\text { Time at which the shortage starts, } \\
(\text { decision variable }) 0 \leq t_{1} \leq T\end{array}$ \\
\hline$c_{1}$ & Holding cost per unit per time unit & $c_{2}$ & Purchase cost per unit \\
\hline$c_{3}$ & Ordering cost per order & $c_{4}$ & Shortage cost per unit per time unit \\
\hline$C_{5}$ & Cost of lost sales per unit & $\theta$ & Deterioration rate \\
\hline$C_{H}$ & Inventory holding cost per cycle & $C_{D}$ & Deterioration cost per cycle \\
\hline$C_{S}$ & Shortage cost per cycle & $C_{L}$ & Lost sales cost per cycle \\
\hline$T-\mathrm{t}_{1}$ & Length of waiting time & $W$ & Maximum inventory level during $T$ \\
\hline $\mathrm{D}$ & Constant Demand in $\left[\mathrm{t}_{1}, \mathrm{~T}\right]$ & \multicolumn{2}{|c|}{} \\
\hline
\end{tabular}

Table 1: Notations for variables and constants 


\begin{tabular}{|c|c|}
\hline$D_{B}$ & Max amount of demand backlogged during $T$ \\
\hline$Q$ & $\left(=W+D_{B}\right)$ order quantity during $T$ \\
\hline $\mathrm{C}$ & Average total cost per time unit per cycle \\
\hline $\mathrm{X}^{*}$ & Optimal value of $\mathrm{X}$, where $\mathrm{X}$ is any variable \\
\hline$I(t)$ & Inventory level at time, $0 \leq t \leq T$ \\
\hline$I_{1}(t)$ & Inventory level for the time-range $0 \leq t<t_{1}$ \\
\hline$I_{2}(t)$ & Inventory level for the time-range $t_{1} \leq t \leq T$ \\
\hline
\end{tabular}

Table 2: Notations for parameters to be calculated in model

\subsection{Assumptions}

1. Demand rate, $\mathrm{R}(\mathrm{t})=\left\{\begin{array}{c}\alpha_{0}+\beta t \text {, for } 0 \leq t<t_{1} \\ D, \text { for } t_{1} \leq t \leq T\end{array}\right.$, where $\alpha_{0}>0, \beta>0$ and $D>0$ are arbitrary constants.

2. Inventory system involves only one item.

3. Planning horizon is infinite.

4. Lead time is zero, i.e., there is no time-lag in the delivery of an order.

5. Rate of deterioration is constant, $\theta(0<\theta<1)$, and it occurs as soon as items are received in inventory. There is no replacement or repair of deteriorated units.

6. For the time-range $t_{1} \leq t \leq T$, a shortage is allowed which is partially backlogged with backorder rate: $\mathrm{B}(\mathrm{t})=\frac{1}{1+\delta(\mathrm{T}-\mathrm{t})}$

The backlogging parameter $\delta$ is a positive constant. For the special case with

$\delta=0, \mathrm{~B}(\mathrm{t})=1$, that is, the fully backlogged case. In the proposed model, we assume $\delta<1$ for a $2^{\text {nd }}$ order approximation of Taylor's series (i.e., $2^{\text {nd }}$ order of a Taylor Polynomial).

7. Holding cost is a linear function of time: $\mathrm{c}_{1}(\mathrm{t})=\mu \mathrm{t}$, where $\mu>0$ is the holding cost scale parameter.

\section{Formulation of inventory model}

The objective of the model is to determine the optimal order quantity in order to keep the total relevant cost as low as possible. The inventory is replenished at time $\mathrm{t}=0$, when the inventory level is at its maximum, $W$. Now, due to both demand for the item and its deterioration, the inventory level starts decreasing during the period $\left[0, t_{1}\right]$, and finally reaches zero, when $t=t_{1}$. Further, during the period $\left[t_{1}, T\right]$, shortages are allowed, and demand is assumed to be partially backlogged. The representation of the inventory system at any time is shown in Figure 1. 


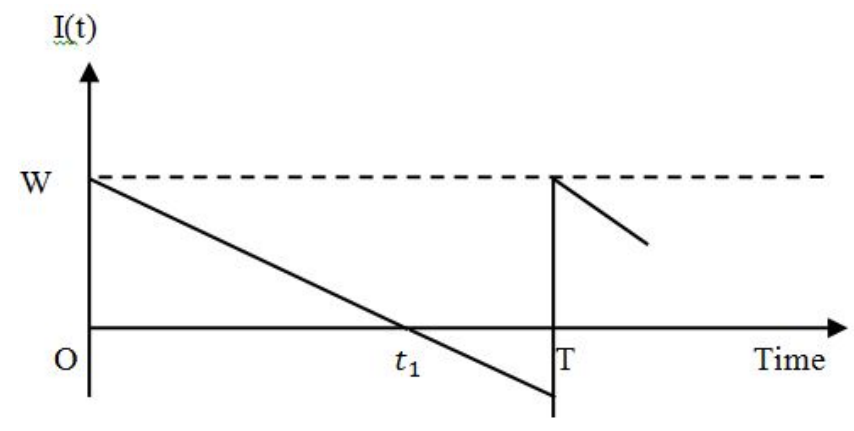

Figure 1: Graphical representation of the inventory system

The governing differential equations during periods $\left[0, t_{1}\right]$ and $\left[t_{1}, T\right]$, are respectively given by:

$$
\begin{aligned}
& \frac{d I_{1}(t)}{d t}+\theta . I_{1}(t)=-\left(\alpha_{0}+\beta t\right) \text {, for } 0 \leq t<t_{1}, \\
& \text { and } \frac{d I_{2}(t)}{d t}=\frac{-D}{1+\delta(\mathrm{T}-\mathrm{t})}, \quad \text { for } t_{1} \leq t \leq T \\
& \text { with boundary conditions: } \left.\begin{array}{c}
I_{1}\left(t_{1}\right)=I_{2}\left(t_{1}\right)=0 \\
I_{1}(0)=W
\end{array}\right\}
\end{aligned}
$$

The objective of this inventory problem is to determine the order quantity and length of ordering cycle in order to keep the total relevant costs as low as possible. That is, to determine $Q^{*}$ and $T^{*}$ so that the total cost is minimized. Let us consider two cases:

\section{Case I: $0 \leq t<t_{1}$}

In this case, the inventory level decreases due to demand as well as deterioration, where the inventory level is governed by (1). Using the boundary conditions (3), the solution of (1) is given by

$$
I_{1}(t)=-\frac{\alpha_{0}}{\theta}-\frac{\beta}{\theta} t+\frac{\beta}{\theta^{2}}+\left(\frac{\alpha_{0}}{\theta}+\frac{\beta}{\theta} t_{1}-\frac{\beta}{\theta^{2}}\right) e^{\theta\left(t_{1}-t\right)}, 0 \leq t<t_{1}
$$

So the maximum inventory level for each cycle is

$$
W=I_{1}(0)=-\frac{\alpha_{0}}{\theta}+\frac{\beta}{\theta^{2}}+\left(\frac{\alpha_{0}}{\theta}+\frac{\beta}{\theta} t_{1}-\frac{\beta}{\theta^{2}}\right) e^{\theta t_{1}}
$$

\section{Case II: $t_{1} \leq t \leq T$}

In this case, the inventory level depends on constant demand. However, a fraction of the demand is backlogged. The inventory level is governed by (2). Using the boundary conditions (3), the solution of (2) is given by

$$
I_{2}(t)=\frac{D}{\delta}\left[\log \{1+\delta(\mathrm{T}-\mathrm{t})\}-\log \left\{1+\delta\left(\mathrm{T}-t_{1}\right)\right\}\right], t_{1} \leq t \leq T
$$

Setting $t=T$ in (6), we obtain the maximum amount of backlogged demand per cycle as follows: 


$$
D_{B}=-I_{2}(T)=\frac{D}{\delta} \log \left\{1+\delta\left(T-t_{1}\right)\right\}
$$

So, the order quantity per cycle is given by

$$
\begin{aligned}
Q & =W+D_{B} \\
& =-\frac{\alpha_{0}}{\theta}+\frac{\beta}{\theta^{2}}+\left(\frac{\alpha_{0}}{\theta}+\frac{\beta}{\theta} t_{1}-\frac{\beta}{\theta^{2}}\right) e^{\theta t_{1}}+\frac{D}{\delta} \log \left\{1+\delta\left(T-t_{1}\right)\right\}
\end{aligned}
$$

For $\theta<1$ and $\delta<1$, the Taylor's series expansion yields the following $2^{\text {nd }}$ degree approximations (i.e., $2^{\text {nd }}$ degree Taylor polynomial):

$$
\begin{aligned}
& \mathrm{e}^{\theta \mathrm{t}_{1}} \approx 1+\theta \mathrm{t}_{1}+\frac{\theta^{2} \mathrm{t}_{1}^{2}}{2} \text { and } \log \left\{1+\delta\left(\mathrm{T}-\mathrm{t}_{1}\right)\right\} \approx \delta\left(\mathrm{T}-\mathrm{t}_{1}\right)-\frac{\delta^{2}\left(\mathrm{~T}-\mathrm{t}_{1}\right)^{2}}{2} \\
& \text { (8) \& (9) } \Rightarrow Q \approx \alpha_{0} t_{1}+\left(\frac{\alpha_{0} \theta+\beta}{2}\right) t_{1}^{2}+\frac{\beta \theta}{2} t_{1}^{3}+D\left[\left(T-t_{1}\right)-\frac{\delta\left(T-t_{1}\right)^{2}}{2}\right]
\end{aligned}
$$

The inventory holding cost per cycle is given by $C_{H}=\int_{0}^{t_{1}} c_{1}(t) I_{1}(t) d t$

$$
\begin{aligned}
& =\int_{0}^{t_{1}} \mu t\left[-\frac{\alpha_{0}}{\theta}-\frac{\beta}{\theta} t+\frac{\beta}{\theta^{2}}+\left(\frac{\alpha_{0}}{\theta}+\frac{\beta}{\theta} t_{1}-\frac{\beta}{\theta^{2}}\right) e^{\theta\left(t_{1}-t\right)}\right] d t \\
& \approx \mu\left(-\frac{\alpha_{0}}{2 \theta} t_{1}^{2}-\frac{\beta}{3 \theta} t_{1}^{3}+\frac{\beta}{2 \theta^{2}} t_{1}^{2}\right)+\mu\left(\frac{\alpha_{0}}{\theta}+\frac{\beta}{\theta} t_{1}-\frac{\beta}{\theta^{2}}\right)\left(\frac{t_{1}^{2}}{2}\right), \text { by a } 2^{\text {nd }} \text { degree } \\
& \text { approximation of } e^{\theta t_{1}} \\
& \approx \mu\left[-\frac{\alpha_{0}}{2 \theta} t_{1}^{2}-\frac{\beta}{3 \theta} t_{1}^{3}+\frac{\beta}{2 \theta^{2}} t_{1}^{2}+\frac{\alpha_{0}}{2 \theta} t_{1}^{2}+\frac{\beta}{2 \theta} t_{1}^{3}-\frac{\beta}{2 \theta^{2}} t_{1}^{2}\right] \\
& \approx \frac{\mu \beta}{6 \theta} t_{1}^{3}
\end{aligned}
$$

The deterioration cost per cycle is given by

$$
\begin{aligned}
C_{D} & =c_{2}\left[W-\int_{0}^{t_{1}} R(t) d t\right] \\
& =c_{2}\left[-\frac{\alpha_{0}}{\theta}+\frac{\beta}{\theta^{2}}+\left(\frac{\alpha_{0}}{\theta}+\frac{\beta}{\theta} t_{1}-\frac{\beta}{\theta^{2}}\right) e^{\theta t_{1}}-\int_{0}^{t_{1}}\left(\alpha_{0}+\beta t\right) d t\right] \approx \frac{c_{2} \theta}{2}\left(\alpha_{0} t_{1}^{2}+\beta t_{1}^{3}\right)
\end{aligned}
$$

The shortage cost per cycle is given by

$$
\begin{aligned}
C_{S} & =c_{4}\left[-\int_{t_{1}}^{T} I_{2}(t) d t\right] \\
& =-c_{4} \frac{D}{\delta} \int_{t_{1}}^{T}\left[\log \{1+\delta(T-t)\}-\log \left\{1+\delta\left(T-t_{1}\right)\right\}\right] d t \\
& =c_{4} D\left[\frac{T-t_{1}}{\delta}-\frac{1}{\delta^{2}} \log \left\{1+\delta\left(T-t_{1}\right)\right\}\right]
\end{aligned}
$$

The lost sale cost per cycle is given by

$$
C_{L}=c_{5} \int_{t_{1}}^{T}\left[1-\frac{1}{1+\delta(\mathrm{T}-\mathrm{t})}\right] \mathrm{D} d t=c_{5} \mathrm{D}\left[\left(\mathrm{T}-t_{1}\right)-\frac{1}{\delta} \log \left\{1+\delta\left(\mathrm{T}-t_{1}\right)\right]\right.
$$

Hence, the average total cost per unit time per cycle is given by

$$
\begin{aligned}
C & =\frac{1}{T}\left\{C_{H}+C_{D}+c_{3}+C_{S}+C_{L}\right\} \\
\Rightarrow C & =\frac{1}{T}\left[\frac{\mu \beta}{6 \theta} t_{1}^{3}+\frac{c_{2} \theta}{2}\left(\alpha_{0} t_{1}^{2}+\beta t_{1}^{3}\right)+c_{3}+D\left(\frac{c_{4}+\delta c_{5}}{\delta}\right)\left\{T-t_{1}-\frac{\log \left(1+\delta\left(T-t_{1}\right)\right)}{\delta}\right\}\right] \\
& \approx \frac{1}{T}\left[\frac{\mu \beta}{6 \theta} t_{1}^{3}+\frac{c_{2} \theta}{2}\left(\alpha_{0} t_{1}^{2}+\beta t_{1}^{3}\right)+c_{3}+D\left(\frac{c_{4}+\delta c_{5}}{\delta}\right) \frac{\delta}{2}\left(T-t_{1}\right)^{2}\right] \\
& \approx \frac{1}{T}\left[\frac{\mu \beta}{6 \theta} t_{1}^{3}+\frac{c_{2} \theta}{2}\left(\alpha_{0} t_{1}^{2}+\beta t_{1}^{3}\right)+c_{3}+\frac{D}{2}\left(c_{4}+\delta c_{5}\right)\left(T-t_{1}\right)^{2}\right]
\end{aligned}
$$



demand and holding cost: An interval number approach

\section{The crisp (or deterministic) model}

Hence, the proposed model can be written as

$$
\begin{array}{ll}
\text { Minimize } & C=\frac{1}{T}\left[\frac{\mu \beta}{6 \theta} t_{1}^{3}+\frac{c_{2} \theta}{2}\left(\alpha_{0} t_{1}^{2}+\beta t_{1}^{3}\right)+c_{3}+\frac{D}{2}\left(c_{4}+\delta c_{5}\right)\left(T-t_{1}\right)^{2}\right] \\
\text { Subject to } & T-t_{1} \geq 0, t_{1} \geq 0, T \geq 0
\end{array}
$$

This is a single-objective crisp non-linear optimization problem. To achieve optimal $t_{1}$ and $\mathrm{T}$, the partial derivatives $\mathrm{C}$ with respect to $t_{1}$ and $\mathrm{T}$ are equated to zero. The resulting equations can be solved simultaneously to obtain the optimal values of $t_{1}$ and $\mathrm{T}$.

$$
\begin{gathered}
\frac{\partial C}{\partial t_{1}}=\frac{1}{\mathrm{~T}}\left[\frac{\mu \beta}{2 \theta} t_{1}^{2}+\frac{c_{2} \theta}{2}\left(2 \alpha_{0} t_{1}+3 \beta t_{1}^{2}\right)-D\left(\mathrm{c}_{4}+\delta \mathrm{c}_{5}\right)\left(T-t_{1}\right)\right] \\
\frac{\partial C}{\partial T}=\frac{1}{\mathrm{~T}}\left[D\left(\mathrm{c}_{4}+\delta \mathrm{c}_{5}\right)\left(T-t_{1}\right)\right]-\frac{1}{T^{2}}\left[\frac{\mu \beta}{6 \theta} t_{1}^{3}+\frac{c_{2} \theta}{2}\left(\alpha_{0} t_{1}^{2}+\beta t_{1}^{3}\right)+\mathrm{c}_{3}+\frac{D}{2}\left(\mathrm{c}_{4}+\delta \mathrm{c}_{5}\right)\left(T-t_{1}\right)^{2}\right](17
\end{gathered}
$$

Additionally, it may be observed that

$$
\frac{\partial^{2} C}{\partial t_{1}^{2}} \times \frac{\partial^{2} C}{\partial T^{2}}-\left(\frac{\partial^{2} C}{\partial T \partial t_{1}}\right)^{2}>0 \text { and } \frac{\partial^{2} C}{\partial t_{1}^{2}}>0, \text { and } \frac{\partial^{2} C}{\partial T^{2}}>0
$$

Hence, the solution of (16) is a global minimum of C.

\section{Interval-valued model}

In many real-life applications, the uncertainties of parameter-values are expressed in terms of intervals. First, let us assume that inventory-exhausting time $t_{1}$ is uncertain, and let it be described by $t_{1}=\left[t_{1 L}, t_{1 R}\right]$. Also let the cycle time $\mathrm{T}$ be replaced by the interval number $\left[T_{L}, T_{R}\right]=[T-\varepsilon, T+\varepsilon]$, where $\mathrm{T}$ is the deterministic value of cycle time and $\varepsilon \geq 0$ is any real number. The basic arithmetic operations on interval numbers are given in [19].

Then, holding cost per cycle is given by $C_{H}=\left[C_{H L}, C_{H R}\right]$,

$$
\text { where } C_{H L}=\frac{\mu \beta}{6 \theta} t_{1 L}^{3}
$$

Total deterioration cost per cycle is given by $C_{D}=\left[C_{D L}, C_{D R}\right]$,

$$
\text { where } C_{D L}=\frac{c_{2} \theta}{2}\left(\alpha_{0} t_{1 L}^{2}+\beta t_{1 L}^{3}\right)
$$

Total shortages cost per cycle is given by $C_{S}=\left[C_{S L}, C_{S R}\right]$,

$$
\text { where } C_{S L}=c_{4} \mathrm{D}\left[\frac{T_{L}-t_{1 L}}{\delta}-\frac{1}{\delta^{2}} \log \left\{1+\delta\left(T_{L}-t_{1 L}\right)\right\}\right]
$$


Total lost sale cost per cycle is given by

$$
\begin{aligned}
C_{L} & =\left[C_{L L}, C_{L R}\right], \\
\text { where } C_{L L} & =c_{5} \mathrm{D}\left[\left(T_{L}-t_{1 L}\right)-\frac{1}{\delta} \log \left\{1+\delta\left(T_{L}-t_{1 L}\right)\right\}\right]
\end{aligned}
$$

The expressions for $C_{H R}, C_{D R}, C_{S R}$ and $C_{L R}$ may be obtained from the expressions $C_{H L}, C_{D L}, C_{S L}$ and $C_{L L}$ on replacing the suffices $L$ by $R$ and $R$ by $L$ respectively. Therefore, the average total cost per unit time per cycle is given by

$$
\begin{aligned}
& C=\frac{1}{\mathrm{~T}}\left\{\mathrm{C}_{\mathrm{H}}+\mathrm{C}_{\mathrm{D}}+\mathrm{C}_{3}+\mathrm{C}_{\mathrm{S}}+\mathrm{C}_{\mathrm{L}}\right\} \\
&=\frac{\left[C_{H L}, C_{H R}\right]+\left[C_{D L}, C_{D R}\right]+\left[c_{3 L}, C_{3 R}\right]+\left[C_{S L}, C_{S R}\right]+\left[C_{L L}, C_{L R}\right]}{\left[T_{L}, T_{R}\right]} \\
&=\frac{\left[C_{H L}+C_{D L}+c_{3 L}+C_{S L}+C_{L L}, C_{H R}+C_{D R}+c_{3 R}+C_{S R}+C_{L R}\right]}{\left[T_{L}, T_{R}\right]} \\
&=\left[\frac{\left(C_{H L}+C_{D L}+c_{3 L}+C_{S L}+C_{L L}\right)}{T_{R}}, \frac{\left(C_{H R}+C_{D R}+C_{3 R}+C_{S R}+C_{L R}\right)}{T_{L}}\right] \\
&=\left[X_{L}, X_{R}\right], \\
& \text { where } \quad X_{L}=\frac{\left(C_{H L}+C_{D L}+c_{3 L}+C_{S L}+C_{L L}\right)}{T_{R}} \\
&=\frac{\frac{\mu \beta}{6 \theta} t_{1 L}^{3}+\frac{c_{2} \theta}{2}\left(\alpha_{0} t_{1 L}^{2}+\beta t_{1 L}^{3}\right)+c_{3 L}+c_{4} \mathrm{D}\left[\frac{T_{L}-t_{1 L}}{\delta}-\frac{1}{2} \log \left\{1+\delta\left(T_{L}-t_{1 L}\right)\right\}\right]+c_{5} \mathrm{D}\left[\left(T_{L}-t_{1 L}\right)-\frac{1}{\delta} \log \left\{1+\delta\left(T_{L}-t_{1 L}\right)\right\}\right]}{T_{R}}
\end{aligned}
$$

and

$$
\begin{gathered}
X_{R}=\frac{\left(C_{H R}+C_{D R}+c_{3 R}+C_{S R}+C_{L R}\right)}{T_{L}}= \\
\frac{\frac{\mu \beta}{6 \theta} t_{1 R}^{3}+\frac{c_{2} \theta}{2}\left(\alpha_{0} t_{1 R}^{2}+\beta t_{1 R}^{3}\right)+c_{3 R}+c_{4} \mathrm{D}\left[\frac{T_{R}-t_{1 R}}{\delta}-\frac{1}{\delta^{2}} \log \left\{1+\delta\left(T_{R}-t_{1 R}\right)\right\}\right]+c_{5} \mathrm{D}\left[\left(T_{R}-t_{1 R}\right)-\frac{1}{\delta} \log \left\{1+\delta\left(T_{R}-t_{1 R}\right)\right\}\right.}{T_{L}}
\end{gathered}
$$

The multi-objective optimization problem is formulated as follows:

$$
\begin{aligned}
\text { Minimize } & {\left[X_{L}, X_{R}\right] } \\
\text { where } & X_{L}=\frac{\left(C_{H L}+C_{D L}+c_{3 L}+C_{S L}+c_{L L}\right)}{T_{R}}, \\
& X_{R}=\frac{\left(C_{H R}+C_{D R}+c_{3 R}+C_{S R}+C_{L R}\right)}{T_{L}}, 0 \leq t_{1 L} \leq t_{1 R}<\mathrm{T}
\end{aligned}
$$

Several methods have been proposed for solving multi-criteria decisionmaking problems. The weighted sum method (WSM) is the best known and simplest multi-criteria decision making method for evaluating a number of alternatives in terms of a number of decision criteria. Therefore, WSM is considered to solve problem (26) and can be written as

$$
\begin{aligned}
\text { Minimize } & \left(w_{1} X_{L}+w_{2} X_{R}\right) \\
\text { Subject to } & w_{1}+w_{2}=1, \quad 0 \leq w_{1} \leq 1, \quad 0 \leq w_{2} \leq 1
\end{aligned}
$$

Here $w_{1}$ and $w_{2}$ are the weights corresponding to the objectives functions $X_{L}$ and $X_{R}$. If all of the weights are positive, the minimum of (27) is the Pareto optimal. 
Now, in the next section, we will solve a numerical example to illustrate the method.

\section{Numerical example}

To illustrate the proposed model, the following input data is considered:

Let the demand rate, $R(t)=\left\{\begin{array}{c}\alpha_{0}+\beta t \text {, for } 0 \leq t<t_{1} \\ D, \text { for } t_{1} \leq t \leq T\end{array}\right.$,

where $\alpha_{0}=15, \beta=12$, and $D=10$. Also let $\mu=1, \quad \theta=0.04, \delta=0.5, c_{2}=$ $1.5, c_{3}=50, c_{4}=5, c_{5}=10$.

\subsection{Example of the crisp (or deterministic) model}

$$
\begin{aligned}
\text { Minimize } & C=\frac{1}{T}\left\{50 t_{1}^{3}+0.03\left(15 t_{1}^{2}+12 t_{1}^{3}\right)+50\left(T-t_{1}\right)^{2}+50\right\} \\
\text { Subject to } & T-t_{1} \geq 0, t_{1} \geq 0, \text { and } T>0 .
\end{aligned}
$$

In solving the above problem, we obtain $C^{*}=65.4931, t_{1}^{*}=0.6554, T^{*}=1.3103$. Now, at $t_{1}=t_{1}^{*}=0.6554$, and $T=T^{*}=1.3103$, the condition (18) is also satisfied. This proves that the solution $C^{*}=65.4931$ is a global minimum. The cost function $\mathrm{C}$ is also demonstrated graphically (see Figure 2). C is observed to be convex.

\subsection{Example of the interval-valued model}

In this model, let $\left[T_{L}, T_{R}\right]=[1.1,1.5]$ and $\left[c_{3 L}, c_{3 R}\right]=[48,52]$. Then, $X_{L}$ and $X_{R}$ are determined as follows:

$$
\begin{aligned}
& X_{L}=\frac{\left(C_{H L}+C_{D L}+c_{3 L}+C_{S L}+C_{L L}\right)}{1.5}, \\
& X_{R}=\frac{\left(C_{H R}+C_{D R}+c_{3 R}+C_{S R}+C_{L R}\right)}{1.1}
\end{aligned}
$$

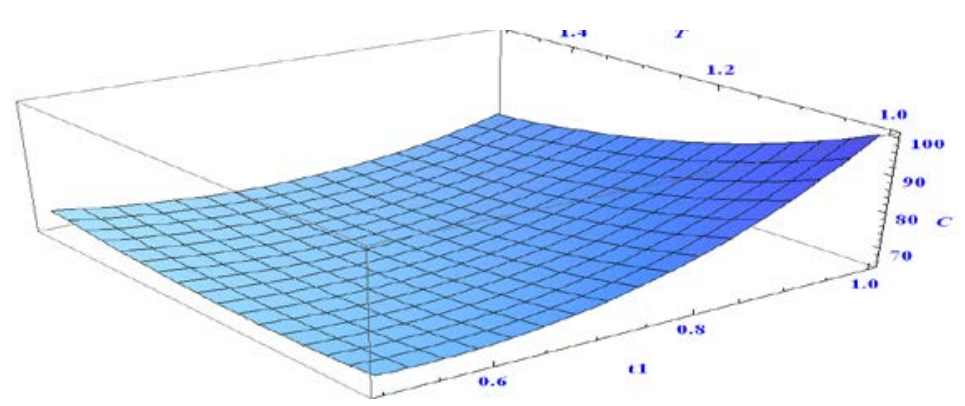

Figure 2: Function $C$ of (28). 


$$
\begin{aligned}
\text { where } & C_{H L}=50 t_{1 L}^{3} \\
C_{D L} & =4.5 t_{1 L}^{2}+3.6 t_{1 L}^{3} \\
C_{S L} & =100\left(1.1-t_{1 L}\right)-200 \log \left\{1+0.5\left(1.1-t_{1 L}\right)\right\} \\
C_{L L} & =100\left(1.1-t_{1 L}\right)-200 \log \left\{1+0.5\left(1.1-t_{1 L}\right)\right\} \\
C_{H R} & =50 t_{1 R}^{3} \\
C_{D R} & =4.5 t_{1 R}^{2}+3.6 t_{1 R}^{3} \\
C_{S R} & =100\left(1.5-t_{1 R}\right)-200 \log \left\{1+0.5\left(1.5-t_{1 R}\right)\right\} \\
C_{L R} & =100\left(1.5-t_{1 R}\right)-200 \log \left\{1+0.5\left(1.5-t_{1 R}\right)\right\} \\
\text { Hence } \quad X_{L} & =\frac{53.6 t_{1 L}^{3}+4.5 t_{1 L}^{2}+48+200\left(1.1-t_{1 L}\right)-400 \log \left\{1+0.5\left(1.1-t_{1 L}\right)\right\}}{1.5}, \\
X_{R} & =\frac{53.6 t_{1 R}^{3}+4.5 t_{1 R}^{2}+52+200\left(1.5-t_{1 R}\right)-400 \log \left\{1+0.5\left(1.5-t_{1 R}\right)\right\}}{1.1}
\end{aligned}
$$

Therefore, the Multi-Objective Non-Linear Programming (MONLP) problem is as follows:

$$
\text { Minimize }\left[X_{L}, X_{R}\right] \text {, with } 0 \leq t_{1 L} \leq t_{1 R}<1.3103 \text {. }
$$

By using weighted-sum method, the multi-objective problem is formulated as Minimize $w_{1} X_{L}+w_{2} X_{R}$, Subject to $w_{1}+w_{2}=1,0 \leq w_{1} \leq 1,0 \leq w_{2} \leq 1$ For equal weights, we obtain: optimal cost $=65.9711$, interval-valued optimal cost $\left[X_{L}^{*}, X_{R}^{*}\right]=[46.2104,85.7318]$. Interval-valued inventory exhausting time $\left[t_{1 L}^{*}, t_{1 R}^{*}\right]=[0.5364,0.6304]$. The value of objective functions: $X_{C}^{*}\left(=\frac{X_{L}^{*}+X_{R}^{*}}{2}\right)$ and $X_{R}^{*} \quad$ can be considered as the minimization of average case and worst case. Therefore, the solution set includes the optimal solution against both the average case and the worst case. The results of the weighted-sum method are summarized in the following Table 3.

\begin{tabular}{|c|c|c|c|}
\hline \multicolumn{2}{|c|}{ Weights } & $\begin{array}{c}\text { Inventory } \\
\text { exhausted time }\end{array}$ & Cost \\
\hline$w_{1}$ & $w_{2}$ & {$\left[t_{L}^{*}, t_{1 R}^{*}\right]$} & {$\left[X_{L}^{*}, X_{R}^{*}\right]$} \\
\hline 1.0 & 0.0 & {$[0.5364,0.5378]$} & {$[46.2105,86.6253]$} \\
\hline $0.90-0.10$ & $0.10-0.90$ & {$[0.5364,0.6304]$} & {$[46.2104,85.7318]$} \\
\hline 0.0 & 1.0 & {$[0.1435,0.6304]$} & {$[55.4074,85.7318]$} \\
\hline
\end{tabular}

Table 3: Results of weighted-sum method 


\subsection{Sensitivity analysis}

The sensitivity analysis of various system parameters is required to observe whether the current solutions remain unchanged, or the current solutions become infeasible. One can analyze the effect of changes in various inventory system parameters on the cost function $C=\left[\mathrm{X}_{\mathrm{L}}, \mathrm{X}_{\mathrm{R}}\right]$. The sensitivity analysis is carried out by changing the value of each of the parameters by $-20 \%,-10 \%$, $10 \%$ and $20 \%$, taking one parameter at a time and keeping the remaining parameters unchanged. The results are displayed in the following Table 4.

\begin{tabular}{|c|c|c|c|}
\hline \multicolumn{2}{|c|}{ Parameter Value } & $t_{1}^{*}=\left[t_{1 L}^{*}, t_{1 R}^{*}\right]$ & $C^{*}=\left[X_{L}^{*}, X_{R}^{*}\right]$ \\
\hline \multirow{4}{*}{$\mu$} & 0.8 & {$[0.5800,0.6871]$} & {$[45.0542,83.1428]$} \\
\hline & 0.9 & {$[0.5569,0.6568]$} & {$[45.6661,84.5208]$} \\
\hline & 1.1 & {$[0.5182,0.6069]$} & {$[46.6989,86.8075]$} \\
\hline & 1.2 & {$[0.5017,0.5860]$} & {$[47.1409,87.7717]$} \\
\hline \multirow{4}{*}{$c_{2}$} & 1.20 & {$[0.5371,0.6312]$} & {$[46.1857,85.6828]$} \\
\hline & 1.35 & {$[0.5368,0.6308]$} & {$[46.1981,85.7073]$} \\
\hline & 1.65 & {$[0.5361,0.6299]$} & {$[46.2227,85.7562]$} \\
\hline & 1.80 & {$[0.5357,0.6295]$} & {$[46.2351,85.7807]$} \\
\hline \multirow{4}{*}{$c_{4}$} & 4.0 & {$[0.5159,0.6041]$} & {$[45.2865,82.9772]$} \\
\hline & 4.5 & {$[0.5264,0.6175]$} & {$[45.7562,84.3728]$} \\
\hline & 5.5 & {$[0.5460,0.6427]$} & {$[46.6504,87.0560]$} \\
\hline & 6.0 & {$[0.5553,0.6547]$} & {$[47.0767,88.3470]$} \\
\hline \multirow{4}{*}{$c_{5}$} & 8 & {$[0.5159,0.6041]$} & {$[45.2865,82.7992]$} \\
\hline & 9 & {$[0.5264,0.6175]$} & {$[45.7562,84.3728]$} \\
\hline & 11 & {$[0.5460,0.6427]$} & {$[46.6504,87.0560]$} \\
\hline & 12 & {$[0.5553,0.6547]$} & {$[47.0767,88.3470]$} \\
\hline \multirow{4}{*}{$\alpha_{0}$} & 12 & {$[0.5369,0.6308]$} & {$[46.1931,85.6992]$} \\
\hline & 13.5 & {$[0.5366,0.6306]$} & {$[46.2018,85.7155]$} \\
\hline & 16.5 & {$[0.5362,0.6301]$} & {$[46.2191,85.7480]$} \\
\hline & 18 & {$[0.5360,0.6299]$} & {$[46.2277,85.7643]$} \\
\hline \multirow{4}{*}{$\beta$} & 9.6 & {$[0.5804,0.6876]$} & {$[45.0449,83.1215]$} \\
\hline & 10.8 & {$[0.5570,0.6570]$} & {$[45.6620,84.5116]$} \\
\hline & 13.2 & {$[0.5180,0.6068]$} & {$[46.7023,86.8148]$} \\
\hline & 14.4 & {$[0.5015,0.5858]$} & {$[47.1470,87.7850]$} \\
\hline \multirow{4}{*}{$D$} & 8 & {$[0.4934,0.5756]$} & {$[44.2978,80.0686]$} \\
\hline & 9 & {$[0.5159,0.6041]$} & {$[45.2865,82.9772]$} \\
\hline & 11 & {$[0.5553,0.6547]$} & {$[47.0767,88.3470]$} \\
\hline & 12 & {$[0.5727,0.6774]$} & {$[47.8914,90.8354]$} \\
\hline \multirow{4}{*}{$\theta$} & 0.032 & {$[0.4947,0.5771]$} & {$[47.3263,88.1783]$} \\
\hline & 0.036 & {$[0.5166,0.6049]$} & {$[46.7390,86.8976]$} \\
\hline & 0.044 & {$[0.5545,0.6538]$} & {$[45.7316,84.6640]$} \\
\hline & 0.048 & {$[0.5711,0.6756]$} & {$[45.2952,83.6808]$} \\
\hline \multirow{4}{*}{$\delta$} & 0.40 & {$[0.5248,0.6197]$} & {$[45.5605,84.1215]$} \\
\hline & 0.45 & {$[0.5308,0.6252]$} & {$[45.8930,84.9462]$} \\
\hline & 0.55 & {$[0.5418,0.6352]$} & {$[46.5145,86.4817]$} \\
\hline & 0.60 & {$[0.5469,0.6397]$} & {$[46.8060,87.1986]$} \\
\hline
\end{tabular}

Table 4: Sensitivity Analysis 
The observations from sensitivity analysis show that the optimal values of interval bounds $X_{L}^{*}$ and $X_{R}^{*}$ (i) are more sensitive to changes in demand parameter $D$ than others, (ii) are relatively less sensitive to initial demand $\alpha_{0}$ and purchasing $\operatorname{cost} c_{2}$ than others, (iii) slightly decrease with an increase in deterioration $\theta$, and their values increase with the increase of other inventory parameters.

If we increase the backlogging parameter $\delta$, then $X_{L}^{*}$ and $X_{R}^{*}$ also increase. Furthermore, when $\delta$ decreases, $X_{L}^{*}$ and $X_{R}^{*}$ also decrease. Hence, for a minimum value of average total cost, $\delta$ should be minimum, i.e., the backorder rate $B(t)$ should be as high as possible. With the existing data, infeasibility is not obtained during sensitivity analysis.

\section{Concluding remarks}

In this paper, we proposed a deteriorating inventory model with time-dependent demand rate and varying holding cost at partial backlogging. Shortages and partial backlogging were allowed. Due to interval-uncertainty, the inventory model was transformed into a form of interval numbers. To solve the obtained multi-objective nonlinear programming problem, the weighted-sum method was applied. Sensitivity analysis revealed that the demand parameter is the most sensitive one. When we move from the optimum in the crisp case to the optimum in the interval case, the total cost slightly increases. On the market, there are certain items (like winter garments, etc.) where during the seasonal period, demand increases with time, and when the season is over, demand decreases sharply and becomes constant. Therefore, the proposed model can be used in inventory control of seasonal items. The investigation on the use of other types of demand functions, interval lead time and the like, can be treated in future papers.

\section{References}

[1] Abad, P. (1996). Optimal pricing and lot-sizing under conditions of perishability and partial backordering. Management Science, 42(8), 1093-1104. doi:10.1287/mnsc.42.8.1093.

[2] Abad, P. (2001). Optimal price and order-size for a reseller under partial backlogging. Computers and Operation Research, 28, 53-65. doi:10.1016/s03050548(99)00086-6.

[3] Chakrabortty, S., Pal, M. and Nayak, P. K. (2013). An algorithm for solution of an interval valued EOQ model. An International Journal of Optimization and Control: Theories \& Applications, 3, 55-64. doi:10.11121/ijocta.01.2013.00113.

[4] Chang, H. and Dye, C. (1999). An EOQ model for deteriorating items with time varying demand and partial backlogging. Journal of the Operational Research Society, 50(11), 1176-1182. doi:10.1057/palgrave.jors.2600801. 
[5] Chung, K. J. and Ting, P.S. (1993). A heuristic for replenishment of deteriorating items with a linear trend in demand. Journal of the Operational Research Society, 44(12), 1235-1241. doi: 10.1057/jors.1993.202.

[6] Dave, U. and Patel, L. (1981). (T, si)-policy inventory model for deteriorating items with time proportional demand. Journal of Operational Research Society, 32(2), 137-142. doi:10.2307/2581261.

[7] Dye, C. (2007a). Determining optimal selling price and lot size with a varying rate of deterioration and exponential partial backlogging. European Journal of Operational Research, 181(2), 668-678. doi: 10.1016/j.ejor.2006.06.029.

[8] Dye, C. (2007b). Joint pricing and ordering for a deteriorating inventory with partial backlogging. Omega, 35(2), 184-189. doi:10.1504/ijmom.2013.058493.

[9] Grzegorzewski, P. (2002). Nearest-interval approximation of a fuzzy number. Fuzzy Sets and Systems, 130(3), 321-330. doi:10.1016/s0165-0114(02)00098-2.

[10] Hong, D. H. and Lee, S. (2002). Some algebraic properties and a distance measure for interval valued fuzzy numbers. Information Sciences, 148, 1-10. doi:10.1016/s0020-0255(02)00265-7.

[11] Ishibuchi, H. and Tanaka, H. (1990). Multi objective programming in optimization of the interval objective function. European Journal of Operational Research, 48, 219-225.

[12] Maity, K. and Maity, M. (2005). Numerical approach of multi-objective optimal control problem in imprecise environment. Fuzzy Optimization and Decision Making, 4(4), 313-330. doi:10.1007/s10700-005-3666-1.

[13] Mahata, G.C. and Goswami, A. (2009). An EOQ model with fuzzy lead time, fuzzy demand and fuzzy cost coefficients. International Journal of Engineering and Applied Sciences, 5, 295-302.

[14] Mahapatra, N. K., Bera, U.K. and Maiti, M. (2012). A production inventory model with shortages, fuzzy preparation time and variable production and demand. American Journal of Operations Research, 2(2), 183-192. doi: 10.4236/ajor.2012.22021.

[15] Mishra, V. K. and Singh, L. S. (2011). Deteriorating inventory model for time dependent demand and holding cost with partial backlogging. International Journal of Management Science and Engineering Management, 6, 267-271.

[16] Moore, R. and Lodwick, W. (2003). Interval analysis and fuzzy set theory. Fuzzy Sets and Systems, 135, 5-9. doi:10.1016/s0165-0114(02)00246-4.

[17] Roy, A. (2008). An inventory model for deteriorating items with price dependent demand and time varying holding cost. Advanced Modeling and Optimization, 10, $25-37$.

[18] Su, J. S. (2007). Fuzzy programming based on interval-valued fuzzy numbers and ranking. International Journal of Contemporary Mathematical Sciences, 2, 393-410.

[19] Skouri, K., Konstantaras, S. and Ganas, I. (2009). Inventory models with ramp type demand rate, partial backlogging and Weibull deterioration rate. European Journal of Operational Research, 192, 79-92. doi:10.1016/j.ejor.2007.09.003.

[20] Shah, N. and Shukla, K. (2009). Deteriorating inventory model for waiting time partial backlogging. Applied Mathematical Sciences, 3, 421-428. 
[21] Soumita K. and Tripti C. (2012). An EOQ model for deteriorating items with fuzzy demand and fuzzy partial backlogging. IOSR Journal of Mathematics, 2(3), 13-20. doi:10.9790/5728-0231320.

[22] Teng, J., Ouyang, L. and Chen, L. (2007). A comparison between two pricing and lot-sizing models with partial backlogging and deteriorated items. International Journal of Production Economics, 105, 190-203. doi:10.1016/j.ijpe.2006.03.003.

[23] Wu, O., Cheng (2005). An inventory model for deteriorating items with exponential declining demand and partial backlogging. Yugoslav Journal of Operations Research, 15(2), 277-288. doi:10.2298/yjor0502277o.

[24] Yao, J. S. and Su, J. S. (2000). Fuzzy inventory with backorder for fuzzy total demand based on interval-valued fuzzy set. European Journal of Operational Research, 124(2), 390-408. doi:10.1016/s0377-2217(99)00177-0.

[25] Zeleny, M. (1982). Multiple Criteria Decision Making. New York: McGraw Hill.

[26] Zimmermann, H. J. (1991). Fuzzy Set Theory and its Applications. Boston: Kluwer Academic Publishers. 